
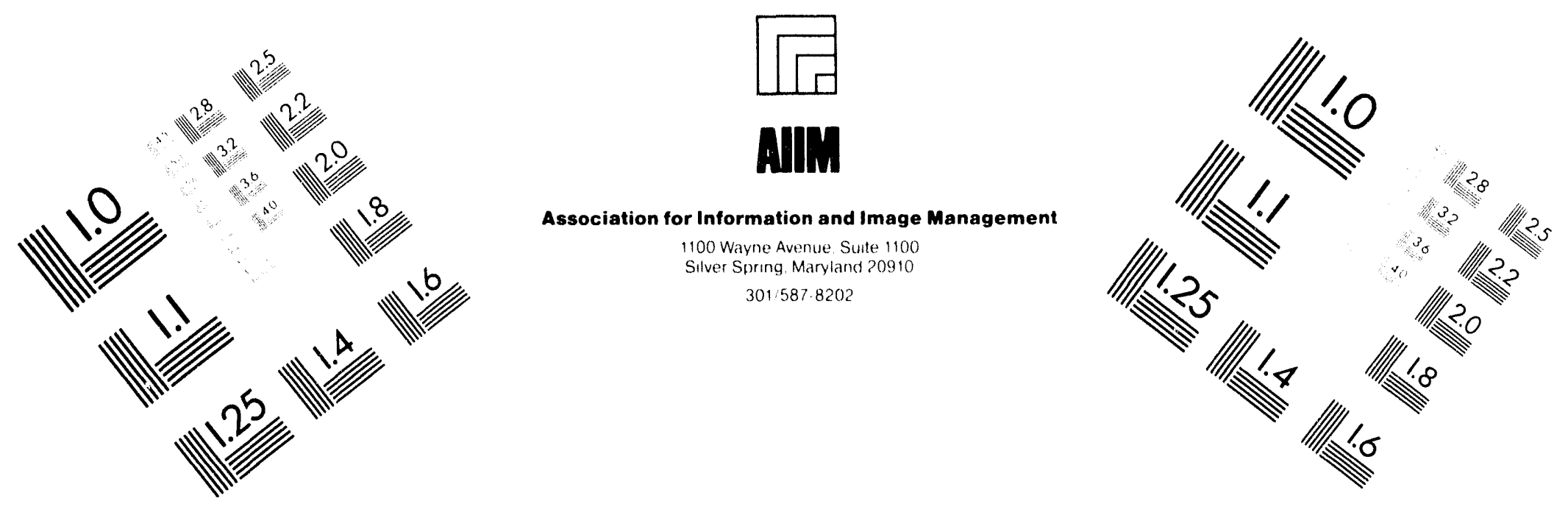

\title{
Centimeter
}

$\mid \begin{aligned} & 2 \\ & \mid\end{aligned}$

Inches
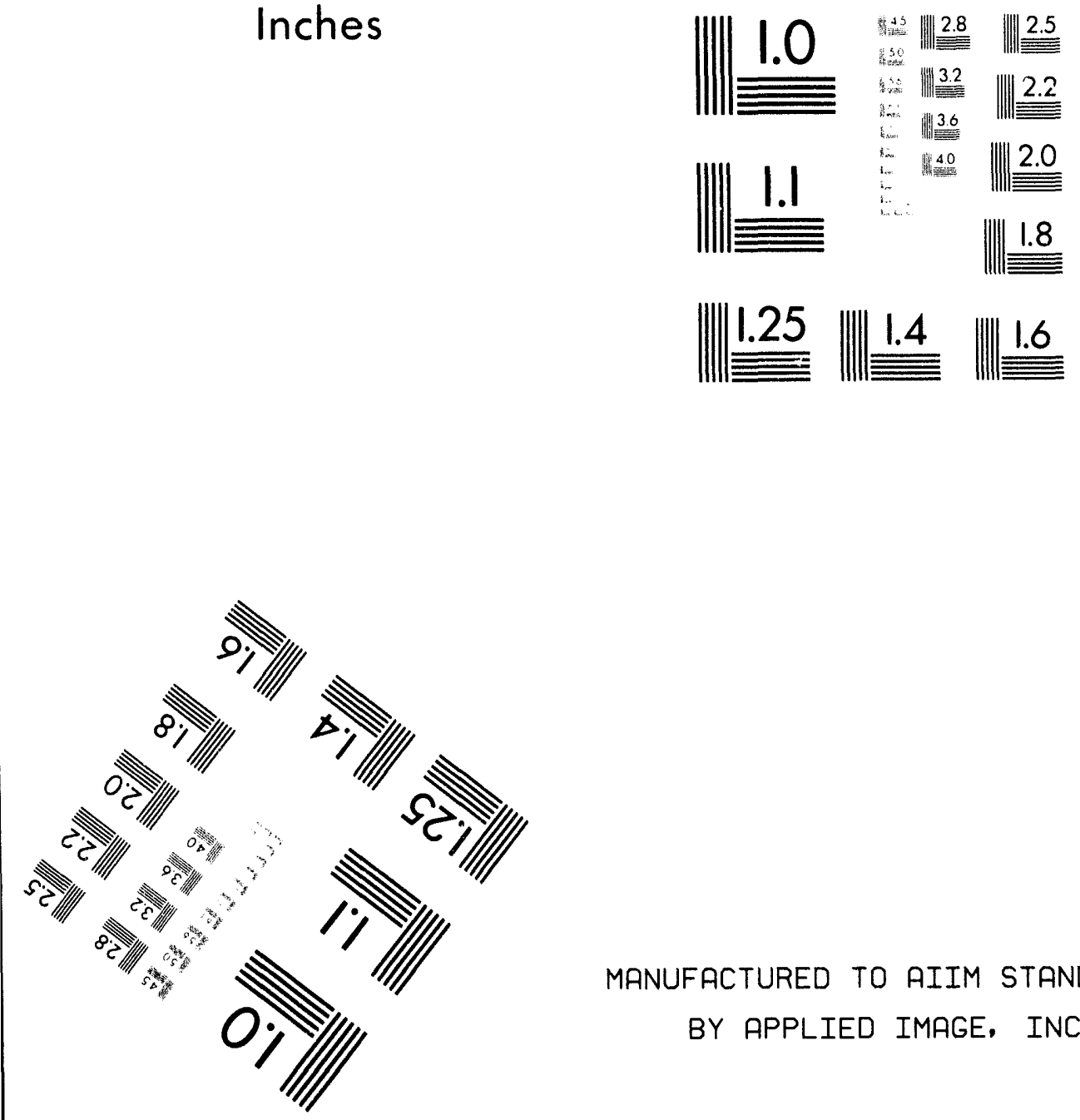

MANUFACTURED TO AIIM STANDARDS

BY APPLIED IMAGE, INC.

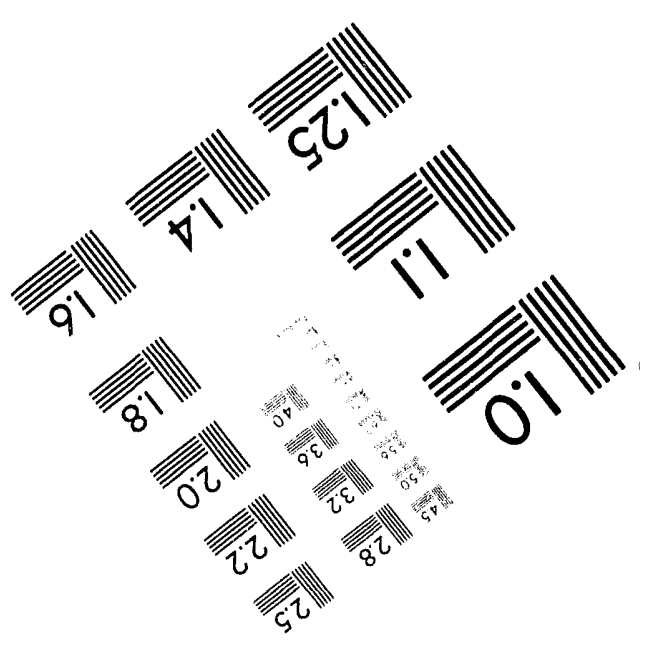



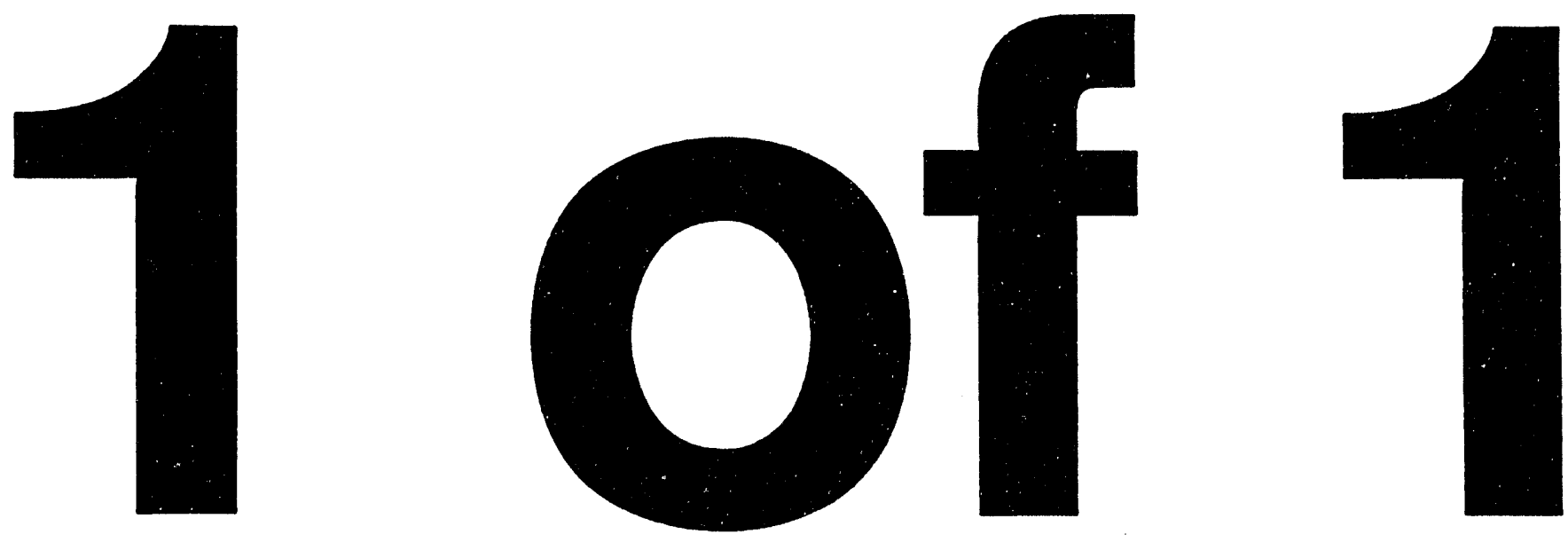
PNL-SA-23148

\section{CHEMICAL SPECIATION OF RADIONUCLIDES MIGRATING IN GROUNDWATER}
D. Robertson
A. Schilk
K. Abel
E. Lepel
C. Thomas
S. Pratt
E. Cooper
P. Harting
R. Killey

April 1994

Presented at the

Third International Conference in Methods and Applications of Radioanalytical Chemistry April 10-16, 1994

Kona, Hawaii

Work supported by the

U.S. Nuclear Regulatory Commission under Contract DE-AC06-76RLO 1830 NRC FIN\# 1935

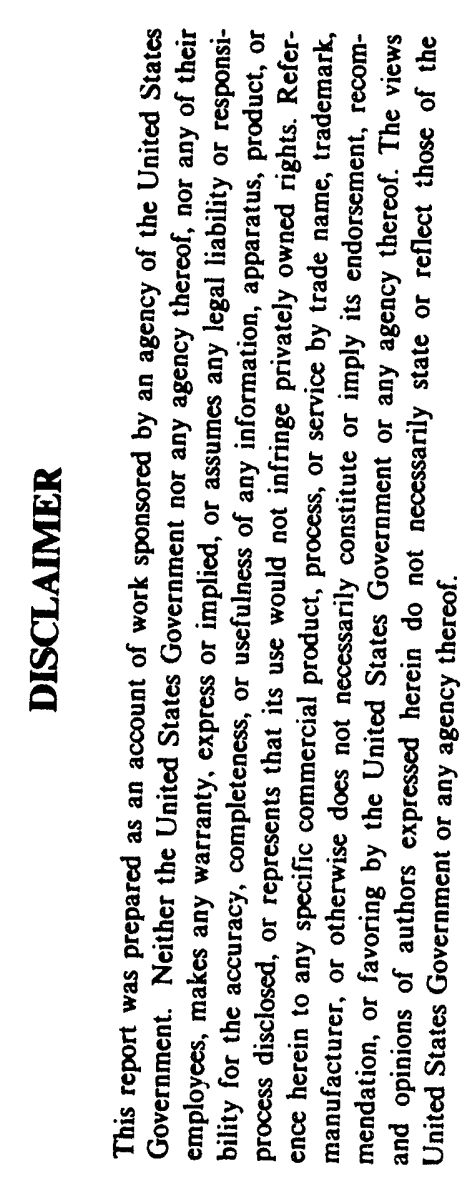

Pacific Northwest Laboratory

Richland, Washington 99352

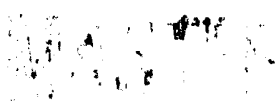


CHEMICAL SPECIATION OF RADIONUCLIDES MIGRATING IN GROUNDWATERS

D. Robertson, A. Schilk, K. Abel, E. Lepel, C. Thomas, S. Pratt Pacific Northwest Laboratory ${ }^{1}$, Richland, WA 99352 (USA)

E. Cooper, P. Hartwig, R. Killey

Chalk River Laboratories, Chalk River, Ontario KOKIJO (Canada)

In order to more accurately predict the rates and mechanisms of radionuclide migration from low-level waste disposal facilities via groundwater transport, ongoing studies are being conducted at field sites at Chalk River Laboratories to identify and characterize the chemical speciation of mobile, long-lived radionuclides migrating in groundwaters. Large-volume water sampling techniques are being utilized to separate and concentrate radionuclides into particulate, cationic; anionic, and nonionic chemical forms. Most radionuclides are migrating as soluble, anionic species that appear to be predominantly organoradionuclide complexes. Laboratory studies utilizing anion exchange chromatography have separated several anionically complexed radionuclides, e.g., ${ }^{60} \mathrm{Co}$ and ${ }^{106} \mathrm{Ru}$, into a number of specific compounds or groups of compounds. Further identification of the anionic organoradionuclide complexes is planned utilizing high resolution mass spectrometry. Large-volume uj.tra-filtration experiments are characterizing the particulate forms of radionuclides being transported in these groundwaters.

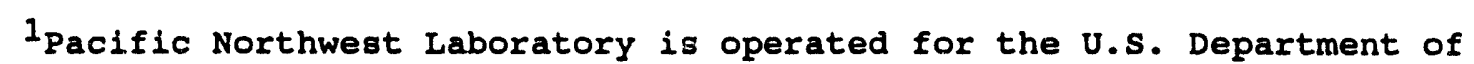
Energy by Battelle Memorial Institute under Contract DE-ACO6-76RIO 1830. 


\section{Introduction}

A major concern regarding the operation of existing and projected nuclear waste disposal sites is the incidence of subterranean radionuclide transport by saturated and/or unsaturated flow. This phenomenon could potentially result in the contamination of public water supply systems as well as uptake by overlying vegetation, thereby directly or indirectly exposing the general public to such materials. Unfortunately, the physico-chemical processes that expedite such transport are still not well understood. To more fully comprehend the mechanisms that determine the extent of radionuclide migration or retardation in existing or proposed low-level waste disposal facilities, it is imperative that those species exhibiting facilitated transport be examined in actual field situations and the results subsequently compared to predictions from laboratory and thermodynamic data. Fundamental information of this sort can then be incorporated into transport models for more accurate predictions of radionuclide migration from repositories, thereby enhancing strategies for site planning or remediation by facilitating mobilization (for pump-and-treat methodologies) or deposition (for ensuring retention).

To assist in the characterization of these processes, an outgoing study is being conducted utilizing field sites at Chalk River Laboratories (CRI) in Ontario, Canada, (see Figure 1) in an attempt to identify and quantify the mobile radionuclide species originating from two separate disposal sites: 1) the Chemical Pit, which has received aqueous wastes containing various radionuclides and chemicals since 1956, and 2) the Waste Management Area "C," a 30-year-old solid low-level waste disposal facility consisting of a series of trenches containing contaminated wastes from CRL and various other facillcies. These mature low- vel waste management and experimental disposal sites are excellent analogues for shallow-land burial facilities located in humid environments, and they provide a unique and invaluable opportunity to study the long-term behavior and transport of a number of important radionuclides, many of which have resided in this shallow groundwater flow system for nearly 40 years. 
It is the purpose of this paper to briefly discuss the experimental procedures utilized in field and laboratory studies at CRI, and to present the preliminary data obtained as a result.

\section{site Description}

The local geology at CRL is made up of a variety of unconsolidated Quaternary sediments of glacial, fluvial and aeolian origin overlying a topographically irregular and locally fractured bedrock of Precambrian granitic gneiss, typical of much of the Canadian Shield. The surficial deposits (generally less than 30 meters in thickness) are fine to medium sands with interbedded layers of clayey silt, both of which are composed largely of quartz and aluminosilicate minerals with associated alteration products, and trace amounts of hydrated oxides of iron and manganese, sulfides, carbonates, and organic matter $1,2,3$. Annual precipitation, approximately $75 \mathrm{~cm}$, is distributed evenly throughout the year and recharges a water table normally less than $5 \mathrm{~m}$ from the ground surface. This has led to the formation of numerous swampy areas throughout the region, which contain bog deposits of peat and other organic matter.

The CRL Liquid Disposal Area (see Figure 2) incorporates a series of lined and unlined trenches excavated from surface sands and includes the Chemical and Reactor Pits. Low-level waste disposals to the former began in the mid-1950s and included a host of radionuclides and chemicals that originated from various operations at the facility ${ }^{2}$. According to Champ ${ }^{1}$, the total inventory of ${ }^{60} \mathrm{Co}$ on the aquifer matrix downgradient of the chemical Pit is $370 \mathrm{GBq}(10 \mathrm{Ci})$, while the quantity of a-emitters disposed of at this site was estimated to be $185 \mathrm{GBq}$ ( $5 \mathrm{Ci}$ ). A chort subsurface flow path extends from this pit to a nearby stream, with a groundwater residence time of 6 months to 2 years and a mean flow rate of 5 to $25 \mathrm{~cm} /$ day. Earlier invegtigations 1,3 identified radioisotopes of Co, $\mathrm{Zr}, \mathrm{Ru}, \mathrm{Sb}, \mathrm{Cs}, \mathrm{Ce}, \mathrm{Eu}, \mathrm{Fe}, \mathrm{Sr}, \mathrm{Ni}, \mathrm{I}, \mathrm{Tc}, \mathrm{Pu}$, $\mathrm{Am}$, and $\mathrm{Cm}$ in downgradient water samples. Nonetheless, routine monitoring of Perch Lake, which receives drainage from this waste pit, indicates that 
radionuclide concentrations do not exceed levels prescribed for permissible drinking water ${ }^{2}$.

The Reactor Pit has received low-level aqueous wastes from CRL's rod storage bays since 1956. Disposed a-emitters total. approximately $580 \mathrm{Gbq}$ $(15.8 \mathrm{Ci})$, while groundwater flow and residence times are essentially equivalent to those observed at the chemical Pit located $200 \mathrm{~m}$ to the northeast. Champ and others' have determined the presence of radioactive Co, $\mathrm{Ru}, \mathrm{Sb}, \mathrm{Cs}, \mathrm{Fe}, \mathrm{Sr}, \mathrm{Ni}, \mathrm{Pu}$, and $\mathrm{Am}$ in the groundwater effluent from this site. Waste Management Area "C" (see Figure 3) includes a series of unlined trenches within a large sand ridge, which forms the southern margin of a nearby lake. This facility is still in operation and has received mixed lowlevel solid wastes from CRL, industry, hospitals, and universities throughout Canada since 1963. Water is discharged from the lake to the southwest via the potentially contaminated subsurface sands and travels at rates of 15 to 30 $\mathrm{cm} /$ day, leading to a total residence time of approximately 2 to 4 years below Area "C"4. Tritium $\left({ }^{3} \mathrm{H}\right)$ is the primary radionuclide of concern at this site in terms of quantity, although significant concentrations of ${ }^{14} \mathrm{C}$ have been detected in the downgradient groundwater and vegetation; ${ }^{60} \mathrm{Co}$ and ${ }^{36} \mathrm{Cl}$ have been observed in very trace amounts in the groundwater as well. Impermeable polyethylene covers were installed over a large portion of this site in 1983 and appear to have eliminated the infiltration of precipitation and consequent release of tritiated water, but ${ }^{14} \mathrm{C}$ is apparently still migrating from the $\operatorname{area}^{4}$.

\section{Experimental}

\section{Field Sampling and Measurements}

Groundwaters were sampled from the Chemical Pit plume in 1983, 1991, and 1993, and from the Area-c plume in 1991 and 1993 from existing multi-l-vel piezometers, which were known from previous investigations to intercept the subsurface plumes of migrating radionuclides. Individual piezometers were 
flushed for about 30 minutes before collection to ensure representative sampling of interstitial waters, and pump flow rates were maintained as low as possible to preclude re-suspension of any microparticulates retained by the aquifer medium. Following the flush procedure, groundwater samples were passed through a sterile prefilter unit, which included a nominal $1.0 \mu \mathrm{m}$ (micrometer) gauze layer followed by $0.8-\mu \mathrm{m}$ and $0.2-\mu \mathrm{m}$ membranes in an attempt to retain a majority of the particulate, or undissolved, materials. During this process, groundwater temperature, $\mathrm{Ph}, \mathrm{Eh}$, dissolved oxygen, alkalinity, and ferric/ferrous iron $\left(\mathrm{Fe}^{3+} / \mathrm{Fe}^{2+}\right)$ concentrations were quantified. Aliquots were also drawn for analyses of trace metals, anions, and organic carbon content.

Prefiltered groundwaters were subsequently passed through a large volume water sampler 5 to facilitate the removal of charged and uncharged soluble species (see Figure 4). This modular unit is composed of six stacked resin or sorbent chambers separated by glass-fiber filter sheets. Water enters the base of the unit and is directed to the first of two cation exchange resin beds (sodium ( $\mathrm{Na}^{+}$) form, 200-400 mesh), the redundant bed being present in case the first is compromised or becomes saturated. Following the cation beds are duplicate layers of anion exchange resin (chloride [ $\mathrm{Cl}^{-}$] form, 200-400 mesh) for retention of negatively charged species, and two activated aluminum oxide $\left(\mathrm{Al}_{2} \mathrm{O}_{3}\right)$ sorbent beds for the removal of those radionuclides that remained in soluble, non-ionic forms. Following the sampling, the individual resin and sorbent beds (as well as the prefilter components) were carefully packaged and shipped to Pacific Northwest Laboratory (PNL) for radiological characterization. Specifically, non-destructive gamma-ray spectrometry was performed by placing the filters, resins, and aluminum oxide in standardized geometries and counting them with a lithium-drifted or intrinsic germanium detector. Aliquots of the above were then leached with appropriatr reagents, and the resulting solutions were subjected to various radiochemical separation procedures for the quantification of radioisotopes that were not amenable to direct gamma analysis. 
The microparticulate content of the groundwater from the Chemical Pit plume was characterized during the 1993 sampling using ultrafiltration techniques. An Amicon (model DClOL) hollow-fiber ultrafiltration system was used with four separate size-cutoff fiber cartridges in an attempt to fractionate various migrating radionuclide species. This methodology was chosen over stirred-cell membrane ultrafiltration because of its ability to process large volumes of groundwater in a relatively short period of time, and to minimize the tendency toward concentration polarization and surface adsorption processes at the membrane/solution boundary (commonly associated with the stirred-cell technique) as a result of the accompanying intra-fiber shear forces.

Sampled groundwater (approximately $170 \mathrm{I}$ total) was added continuously to the system reservoir (see Figure 5) and pumped through a parallel set of two 100,000 molecular weight (MW) cutoff hollow-fiber filter cartridges, thereby retaining and concentrating all species exceeding about $10 \mathrm{~nm}$ or larger, while directing the filtrate to a nearby reservoir. After the total retentate volume dropped below $20 \mathrm{~L}$, deionized water was added to the system reservoir while continuing the recirculation in order to purify the retentate and flush it of any remaining salts. Regulting filtrate(s) were processed as above through $30,000 \mathrm{MW}$ (approx. $5 \mathrm{~nm}$ ), 10,000 MW (approx. $3 \mathrm{~nm}$ ) and 3,000 MW (approx. $1 \mathrm{~nm}$ ) cutoff filters to generate four individual size fractions, which were transported to PNL in light-tight, chilled containers for characterization.

\section{Laboratory Ion Exchange Chromatography studies}

In an effort to separate and identify the soluble anionic radionuclide species migrating in the Chemical Pit groundwater plume, 4-I samples of groundwater were passed through columns of 200-400 mesh AGMPI anion exchange resin to quantitatively retain the anionic radionuclides. The resin columns (16 mm diameter by $25 \mathrm{~cm}$ long) were then eluted, using a gradient elution technique (see Figure 6) in the following sequence: $30 \mathrm{~mL}$ of $\mathrm{Ph} 4.5 \mathrm{HCl}$, 
followed by $500 \mathrm{~mL}$ of a 0 - to $0.5-\mathrm{M} \mathrm{KCl}$ gradient, followed by $100 \mathrm{~mL}$ of $0.1 \mathrm{M}$ HCl. The eluants were passed through a gamma-ray detector and fraction collector to monitor and collect the various anionic radionuclide species. Eluate peak solutions were saved and frozen for gubsequent further characterization by h gh-resolution mass spectrometry for organic constituents.

\title{
Results and Discussion
}

\section{Field Measurements}

\begin{abstract}
Field measurements of physical and chemical parameters for groundwater plumes from the Chemical Pit site and Area C taken during the summer of 1993 are given in Table 1. The groundwater samples from the chemical Pit plumes are slightly acidic and oxidizing in nature near the chemical Pit (CP-4, ES39-B and ES-16 are 10, 22 and $40 \mathrm{M}$, respectively, from the pit). However, as the groundwater flows into the East swamp Area, the groundwater contains very low dissolved oxygen concentrations and high ferrous iron concentrations, which are indicative of less oxidizing conditions. It is interesting to note that the Eh measurements do not reflect the variability of the dissolved oxygen and ferrous iron distributions.

The groundwater plume extending from Area $c$ also exhibited variable dissolved oxygen and ferrous iron concentrations as the groundwater moves away from the waste trenches. This relationship for all of the samples is shown in Figure 7, and illustrates the systematic inverse correlation between dissolved oxygen and ferrous iron concentrations for these groundwaters
\end{abstract}

Chemical speciation of Radionuclides

The results of the large-volume water sampling conducted in 1993 for partitioning the radionuclides into particulate, cationic, anionic, and 
nonionic species are compared with results obtained in 1983 and 1991 from well ES-16 in the groundwater plume extending from the Chemical Pit (see Figures 8 and 9$)$. Total concentrations of ${ }^{60} \mathrm{Co},{ }^{106} \mathrm{Ru}$, and ${ }^{125} \mathrm{Sb}$ were somewhat lower in 1993, but the relative distribution of these radionuclides between particulate, cationic, anionic, and nonionic species has changed very little over time. This indicates that the formation mechanisms of the more abundant mobile anionic species of these radionuclides has apparently not changed over the past ten years. Total $239 / 240 \mathrm{Pu}$ concentrations also dropped between 1983 and 1991 (analyses of the 1993 samples are in progress), but the relative distribution between the predominant anionic form(s) versus cationic forms has not appreciably changed (see Figure 9 ).

It was also of interest to determine if the relative distribution of radionuclides between soluble ionic and nonionic forms changed as the groundwater moved down-gradient from the oxidizing environment of the pit area to the more reducing environment of the swamp area. Figure 10 shows that the relative abundances of cationic, anionic and nonionic forms of ${ }^{60}$ co change very little as the radiocobalt moves from the pit area to the swamp area. Apparently, the rather drastic changes in the oxidizing conditions of the groundwater has little effect on the ionic speciation of ${ }^{60} \mathrm{Co}$. Similar behavior was also noted for ${ }^{106} \mathrm{Ru}$, but ${ }^{125} \mathrm{Sb}$ showed significant changes between nonionic and anionic forms during this migration.

It is suspected that the negatively charged radionuclide species are primarily organoradionuclide complexes formed with 1) organic macromolecules of natural humic and fulvic acids originating from the decomposition of plant and animal residues, and/or 2) anthropogenic organic chelating agents such as ethylenediamine tetraacetic acid (EDTA), a number of which are known to have been disposed of within the Chemical Pit. Other potential forms of these migrating radionuclide-bearing anions may include inorganic colloidal materials (mineraloginally equivalent to the aquifer matrix, with negatively charged surface sites favorable for the retention of cationic radionuclides) and-inorganic radionuclide-complexes composed of common aquo-anion ligands (sulfato-, chloro-, hydroxo- $\left[\mathrm{OH}^{-}\right]$, etc., or combinations thereof). 


\section{Ultrafiltration Measurements}

The results of the ultrafiltration experiment with Es-16 groundwater using the Amicon DClOL hollow fiber ultrafiltration system are given in Table 2. These data suggest that significant amounts of ${ }^{60} \mathrm{Co}$ and ${ }^{106} \mathrm{Ru}$ are associated with a wide range of very small particles that would normally pass through a $0.2-\mu$ prefilter, e.g., particl, ranging from $0.2-\mu$ to $<0.0003-\mu$. These particle sizes are equivalent to molecular weights (MW) ranging from

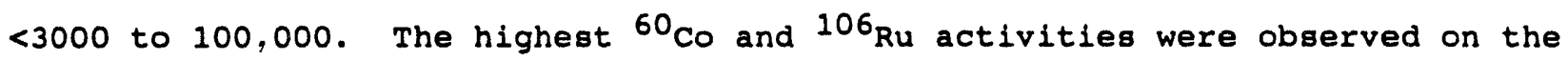
<3000 MW fraction, which would be representative of materials ranging from inorganic simple and complex ions, organic molecules, polymeric species, and small aggregates.

The MW range of 3000 to 10,000 is representative of such materials as fulvic and humic substances and other macromolecules. Particles ranging between 10,000 to $100,000 \mathrm{KW}$ may also be representative of large humic substances, macromolecules, biopolymers, hydrolysis and precipitation products, and mineral substances.

In any case, it is obvious that a significant fraction of certain fission and activation products leached from the chemical Pit are being transported in the groundwater in forms that are consistent with our other observations that suggest organic complexation with natural or synthetic compounds, i.e., fulvic/humic acids, EDTA, carboxylic acids, etc., is an important mobilization mechanism. Further physical and chemical characterization studies are planned with the ultrafiltered concentrated solutions containing the various particle size fractions to further elucidate the nature of these macromolecules.

\section{Laboratory Anion Chromatography Results}

Figures 11 and 12 show the results of the anion chromatography of ES-16 groundwater for ${ }^{60} \mathrm{Co},{ }^{106} \mathrm{Ru}$, and ultraviolet absorbing organic compounds. In these experiments $4 \mathrm{I}$ of groundwater was passed through the anion resin column described in the experimental section to quantitatively retain the predominant 
anionic forms of these radionuclides. Then the gradient elution scheme previously described was used to elute and separate the various anionic radionuclide species. The ${ }^{60} \mathrm{Co}$ and ${ }^{106} \mathrm{Ru}$ eluted as four or five distinct compounds or groups of compounds (aee Figure 11), indicating a rather complex distribution of anionic forms, presumably organoradionuclide complexes composed of fulvic/humic substances and/or synthetic chelating compounds, such as EDTA. The elution curve for the ultraviolet absorbing organic compounds is shown in Figure 12 and overlaps precisely with the major elution peaks for ${ }^{60} \mathrm{Co}$ and ${ }^{106} \mathrm{Ru}$. Preliminary analyses at CRL also show that ${ }^{241_{\mathrm{Am}} \text { and }}{ }^{244} \mathrm{Cm}$ were also present in the main elution peak from Figure 12, suggesting that transuranic radionuclides are also being organically complexed. The solutions from the peak fractions have been saved and frozen and will be analyzed by high-resolution masa spectrometry to help determine the actual organic compounds that form anionic complexes with these radionuclides.

\section{Conclusions}

The field studies conducted at CRL and laboratory studies at PNL and CRL are identifying the physical and chemical speciation of radionuclides migrating from low-level waste disposal sites. Radionuclide mobility is enhanced by the formation of anionic complexes which form in and/or near the disposal site source terms. Inferential evidence suggests that organic complexation by natural fulvic/humic substances and/or synthetic chelators are responsible for the formation of the anionic complexes. Laboratory atudies using gradient elution anion chromatography have identified four or five separate compounds or groups of compounds that represent the anionic forms of ${ }^{60} \mathrm{Co}$ and ${ }^{106} \mathrm{Ru}$ in groundwater from the chemical Pit plume. Solutions from separated elution peaks are being preserved for further characterization by high resolution mass spectrometry to identify the precise organic compounds responsible for the radionuclide complexation. These anionic organic complexes appear to be quite stable and are not significantly altered by the rather drastic changes in the redox conditions observed during groundwater 
transport. Thus, they have whe potential for aignif:cant far-field migration. Ultrafiltration experiments using groundwater from the ES-16 well at the Chemical pit plume indicate that a significant fraction of certain fission and activation products are associated with macrcmolecules which can pass through a $0.2-\mu$ prefilter. These observations are consistent with our hypothesis that natural fulvic/humic substances and/or synthetic chelating materials are forming "soluble" anionic complexes with the radionuclides to increase their mobility in groundwaters.

\section{Acknowledgement:}

Funding for this project was provided by the Waste Management Branch, Division of Engineering, Office of Nuclear Regulatory Research, u.s. Nuclear Regulatory Commission. The authors wish to express their appreciation to Dr. Edward O'Donnell (Project Manager) and Dr. Mel silberberg (Branch chief) for their helpful guidance and suggestions in conducting this work.

Pacific Northwest Laboratory is operated for the U.S. Department of Energy by Battelle Memorial Institute under Contract DE-ACO6-76RLO 1830. 
1. D. Champ, J. Young, D. Robertson, and K. Abel, Water Pollution Research Journal of Canada, 19 (1985) 35.

2. R. Killey and J. Munch, Subsurface contaminant transport from the Liquid Disposal Area, CRNI - (1) Hydrogeology and tritium contamination near the Chemical Pit: Atomic Energy of Canada Iimited Report AECL-7691, 105p $(1984)$.

3. R. Killey, J. McHugh, D. Champ, E. Cooper, and J. Young, Environmental Science and Technology, 18 (1984) 148 .

4. R. Killey and J. Mattie, unpublished data, Chalk River Laboratories, Chalk River, Ontario, Canada KOJ1J0, (1993).

5. D. Robertson, and R. Perkins, Radioisotope ratios in characterizing the movement of different physical and chemical species through natural soils, In: Isotope Ratios as Pollutant Source and Behavior Indicators: International Atomic Energy Agency Symposium, Vienna, pp. 123-133, (1974).

6. A. Schilk, D. Robertson, C. Thomas, E. Lepel, D. Champ, R. Killey, J. Young, and E. Cooper, Contaminated Groundwater Characterization at the Chalk River Laboratories, Ontario, Canada, In: Fourteenth Annual U.S. Department of Energy Low-Level Radioactive Waste Management Conference Proceedings: U.S. Department of Energy Conference, Phoenix, pp. 67-83, (1992) . 
Table 1

FIELD MEASLREMENTS OF GROLNDWATER PARAMIETERS AT CRL SITES. AUGUSTISEPTEMBER 1993

\begin{tabular}{|c|c|c|c|c|c|c|c|c|c|}
\hline Site & Sampling W'cll\# & Sampling Dase & Temp. $\left({ }^{\circ} \mathrm{C}\right)$ & $\Gamma \mathrm{H}$ & $E h(V)$ & $\begin{array}{c}\text { Dissnliced } \mathrm{O}_{2} \\
(\mathrm{mgl})\end{array}$ & $\begin{array}{l}\text { Alkalinity } \\
(m \varrho l)\end{array}$ & $\begin{array}{l}F c^{2+} \\
(u g \eta)\end{array}$ & $\begin{array}{c}\text { Total Fe } \\
\text { (ugl) }\end{array}$ \\
\hline 1. Chemical Pit & ES.39B & $829,9.3$ & 14.5 & 5.90 & +4.35 & 4.90 & 15.0 & $<1.3$ & 7.6 \\
\hline 2. Chemical Pit & ES.16 & $8: 0.93$ & 10.0 & 6.00 & +550 & 0.64 & 14.5 & 60 & 95 \\
\hline 3. Chemical Pit & CP.4 & $8: 30.9 .3$ & 11.0 & 6.20 & +.385 & 3.93 & 13.5 & 5 & 7.6 \\
\hline 4. C.Asea & $C \cdot 213$ & 83193 & 9.5 & 5.90 & +325 & 0.42 & 44.0 & 90 & 135 \\
\hline 5. C-Area & C.112 & $0,01,93$ & 9.5 & 6.00 & +.355 & 1.45 & 75.0 & 16 & 27 \\
\hline
\end{tabular}


Table 2

RADIONUCLIDE CONCENTRATIONS ASSOCIATED WITH ULTRAFILTERABLE

SIZE FRACTIONS IN ES-16 GROUNDWATER USING THE AMICON DC1OL

HOLLOW FIBER ULTRAFILTERATION SYSTEM

\begin{tabular}{|c|c|c|c|c|c|}
\hline \multirow{2}{*}{\multicolumn{2}{|c|}{ Ultrafilterable size Range (MW) }} & \multirow[b]{2}{*}{ Equivalent Size Range $(\mu)$} & \multicolumn{3}{|c|}{ pCi/liter of ES-16 groundwater } \\
\hline & & & ${ }^{60} \mathrm{Co}$ & $106_{\mathrm{Ru}}$ & $125 \mathrm{sb}$ \\
\hline \multicolumn{2}{|l|}{$<3000$} & $<0.0003$ & 383 & 270 & --- \\
\hline & $0.003-0.001$ & 135 & 116 & \\
\hline $10,000-30,000$ & & $0.001-0.003$ & 132 & 136 & -- \\
\hline \multicolumn{2}{|l|}{$30,000-100,000$} & $0.003-0.01$ & 98.2 & 87.9 & 0.68 \\
\hline \multirow{3}{*}{$100,000-0.2 \mu$} & & $0.01-0.2$ & 115 & 89.3 & 0.54 \\
\hline & & Total & 863 & 699 & 1.22 \\
\hline & & Total "Dissolved"* & 1230 & 1400 & 25.7 \\
\hline
\end{tabular}

\footnotetext{
"Total "Dissolved" represents the total amount of radionuclide from $0.2 \mu$ filtered ES-16 groundwater that was sorbed onto cation, anion, and $\mathrm{Al}_{2} \mathrm{O}_{3}$ beds.
} 


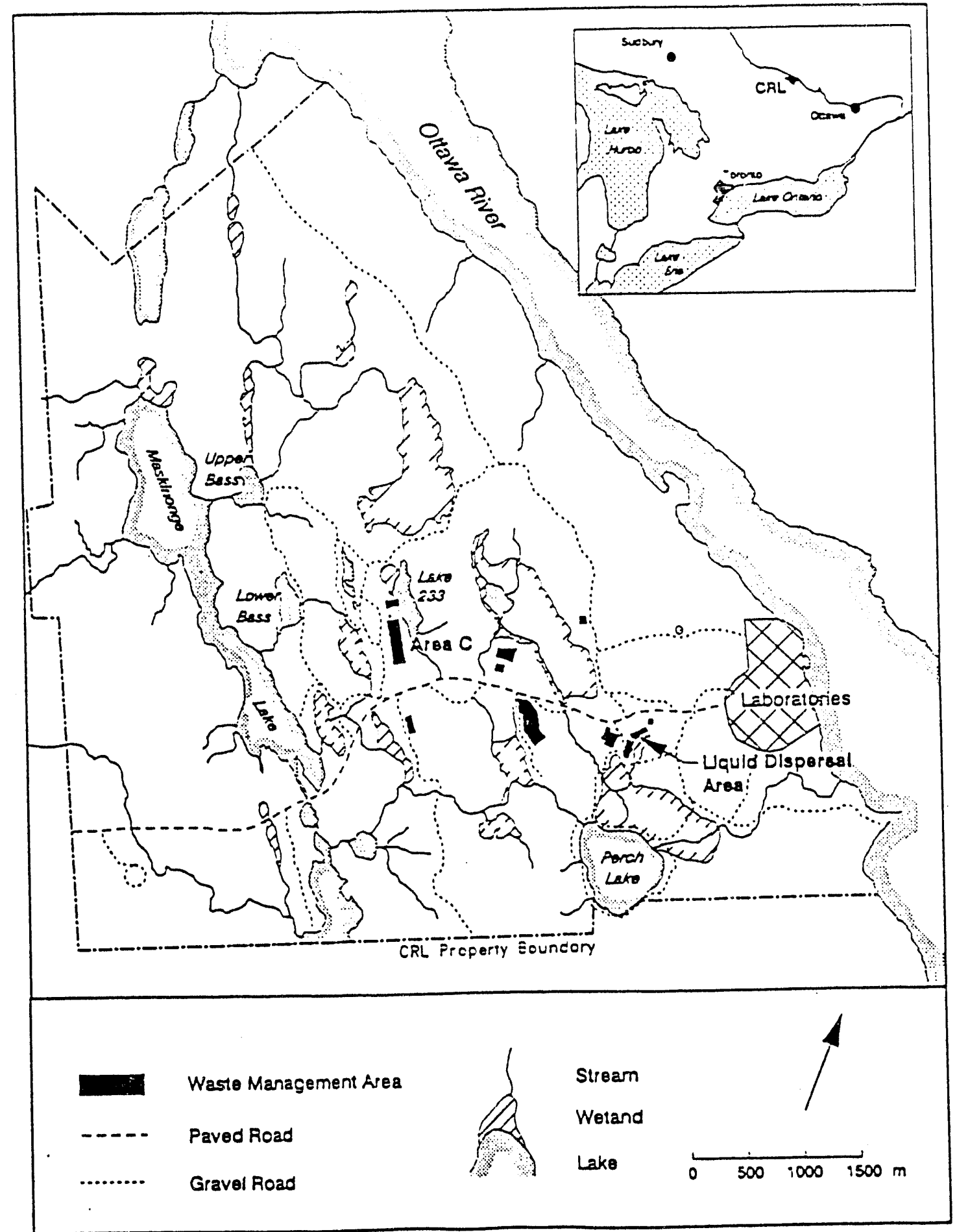

Figure 1 Chalk River Laboratories (CRI) site location map 

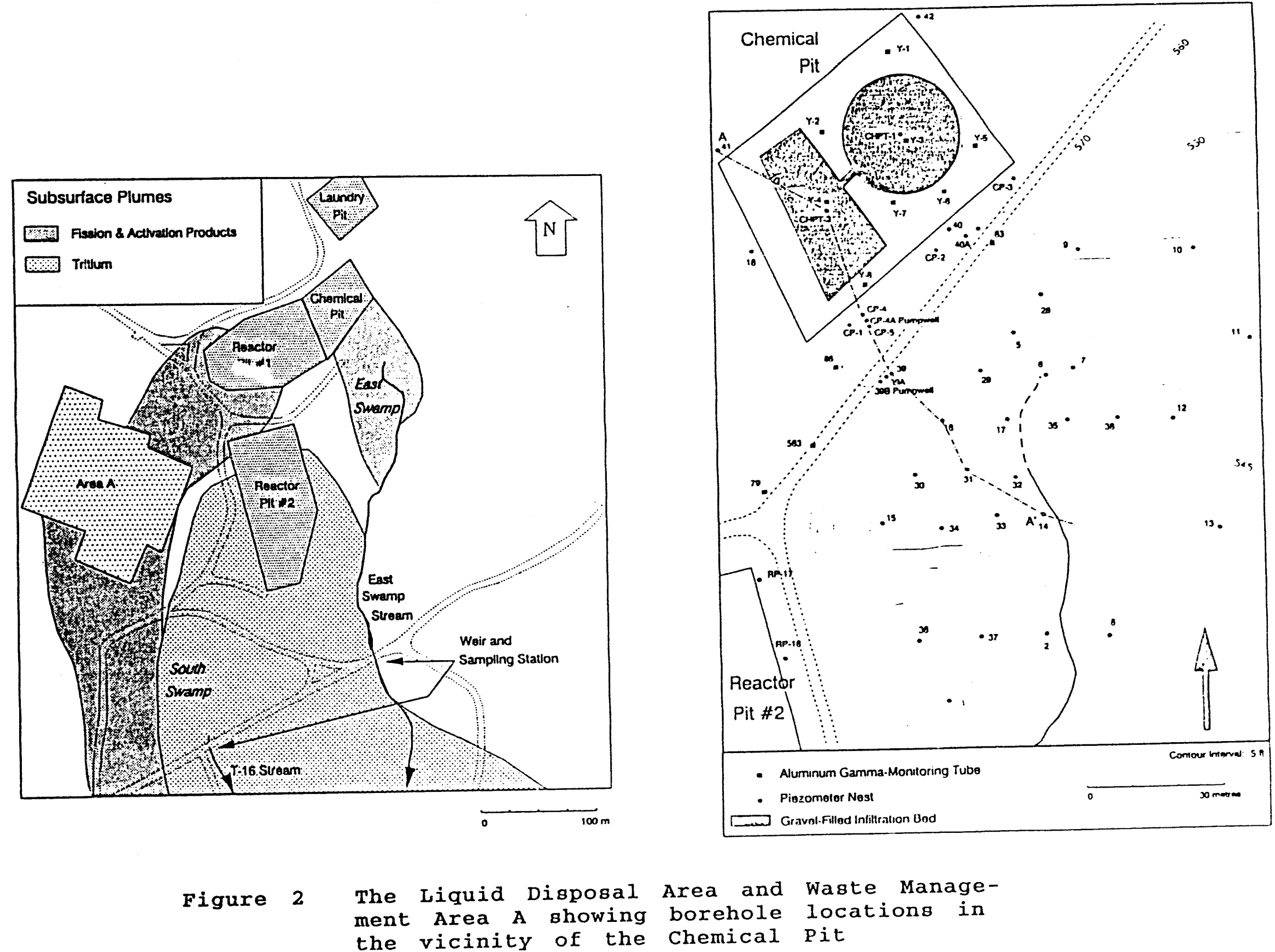

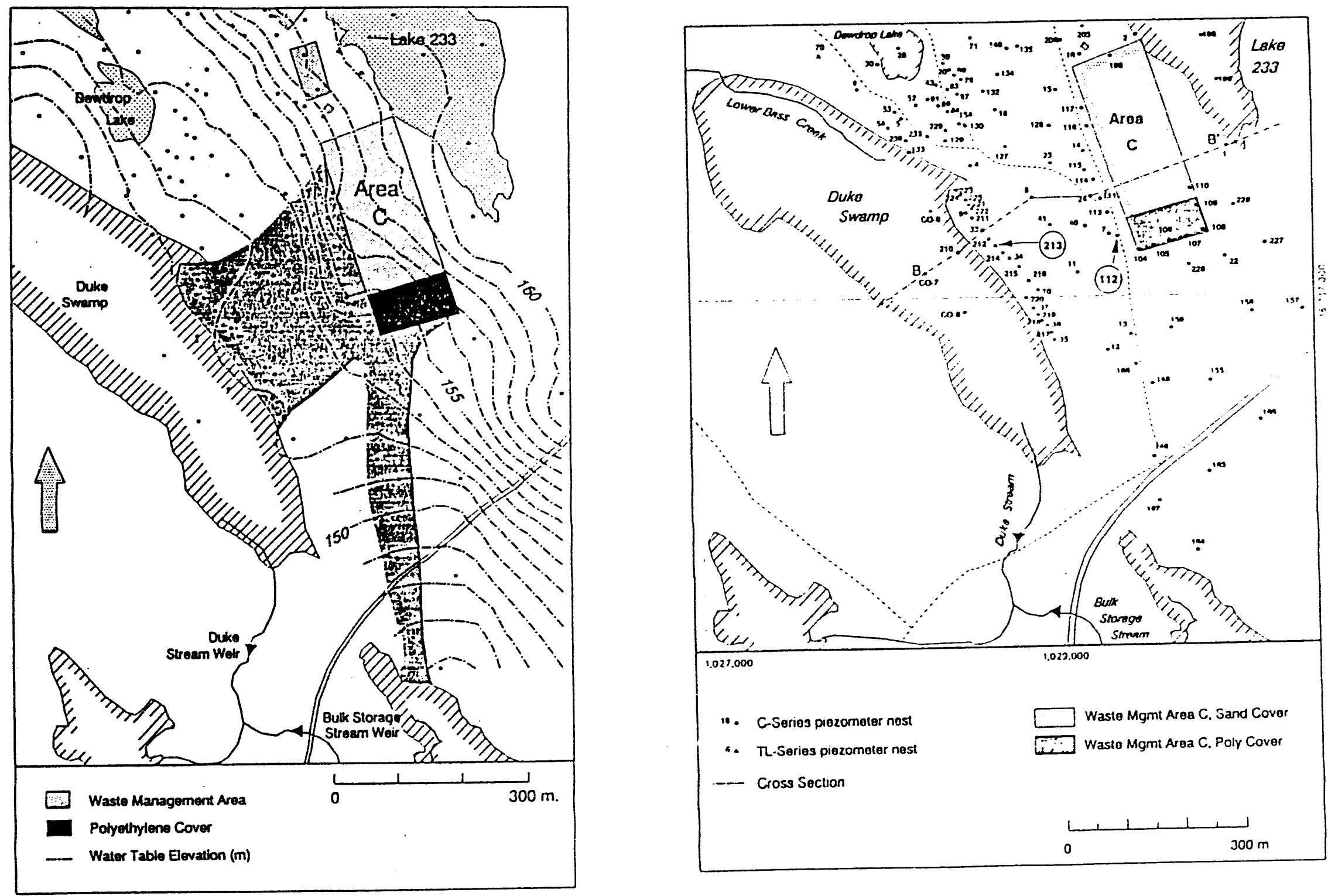

Figure 3 surface hydrology, water table contours, groundwater tritium contamination, and borehole locations near Area C 


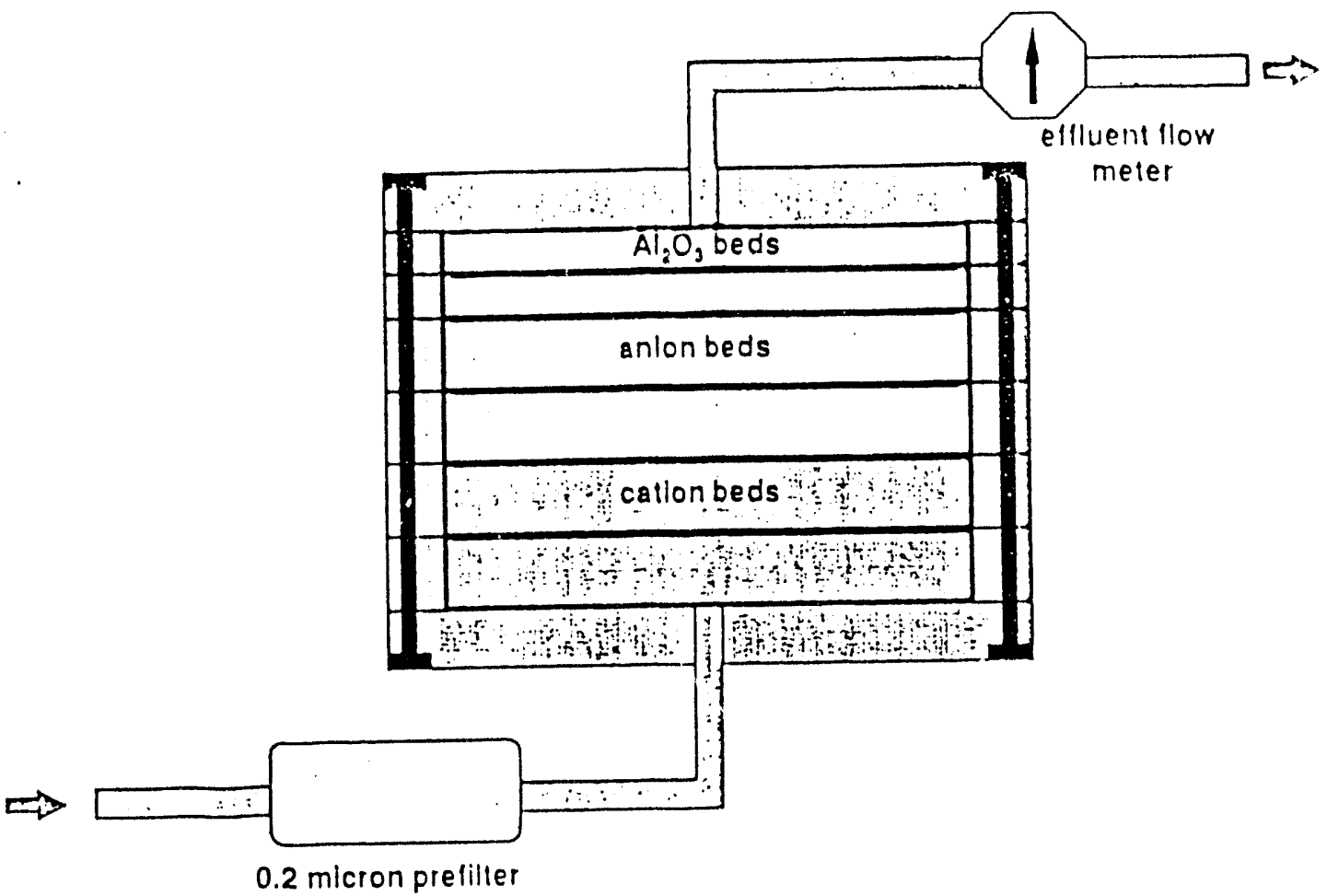

Figure 4 Schematic diagram of the Battelle Large volume water sampler 

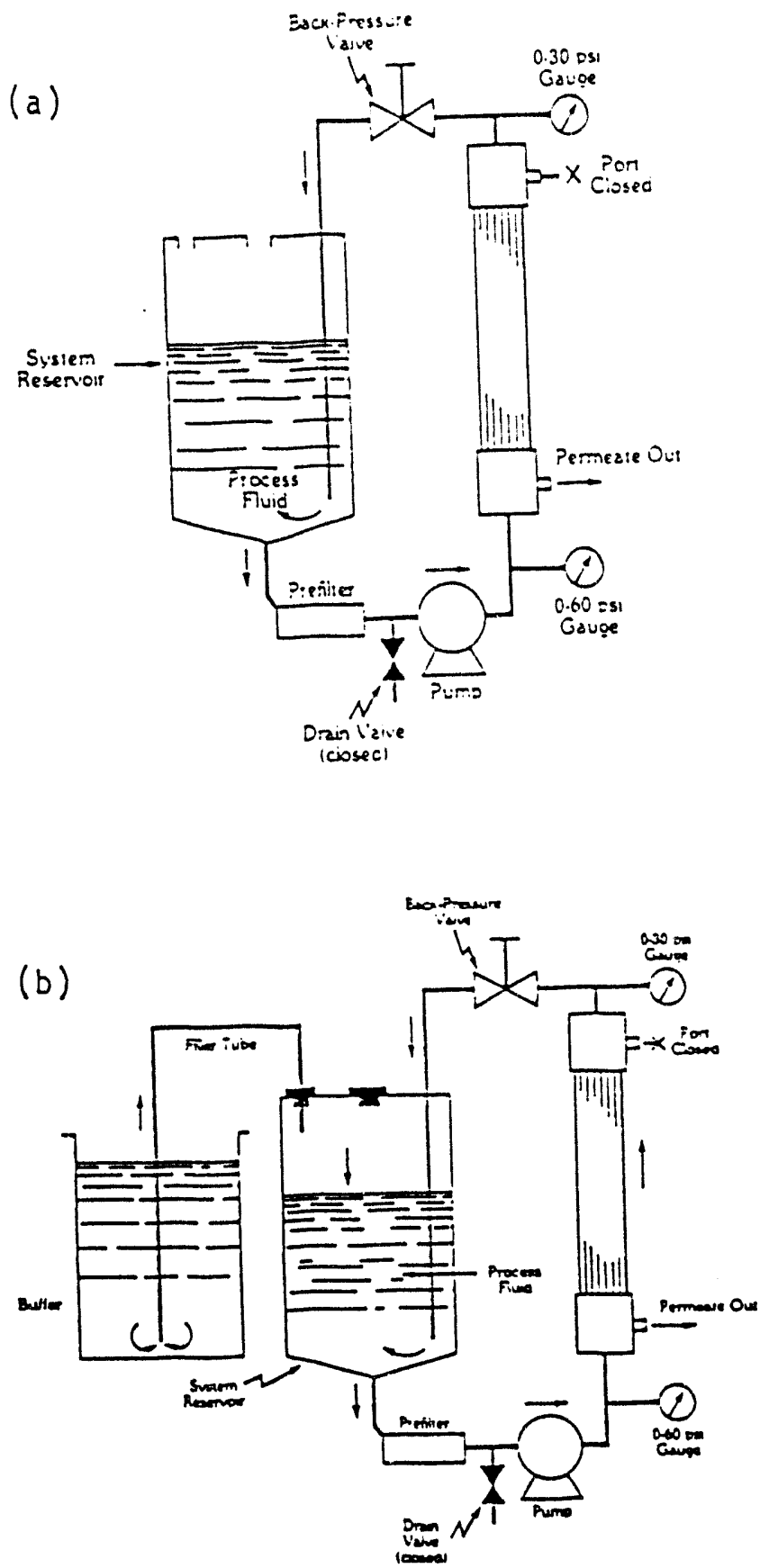

Figure 5 Schematic diagrams of the Amicon DC10L hollow fiber ultrafiltration system showing the concentration (a) and diafiltation (b) modes. 


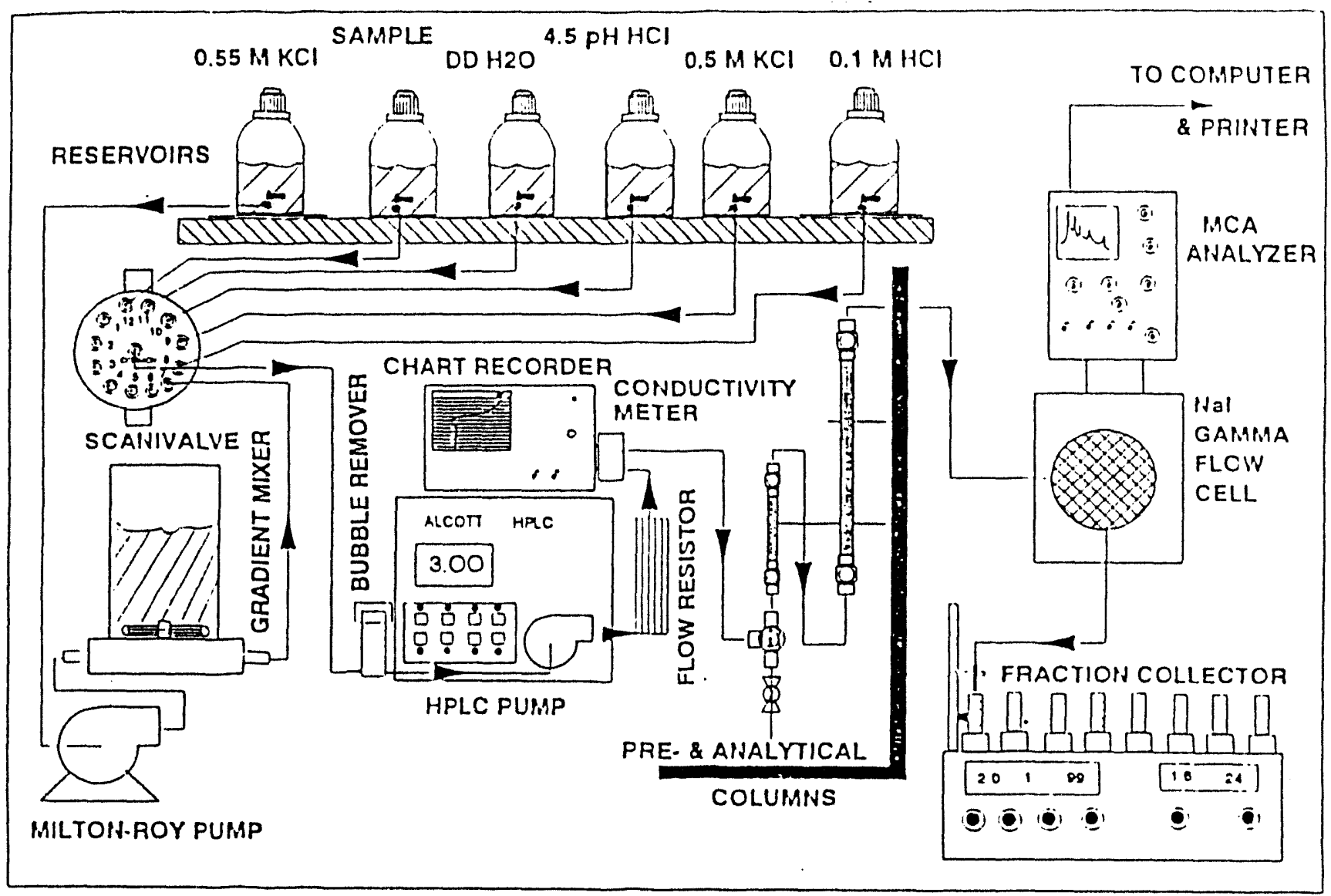

Figure 6 Anion chromatography equipment for radionuclide speciation studies. 


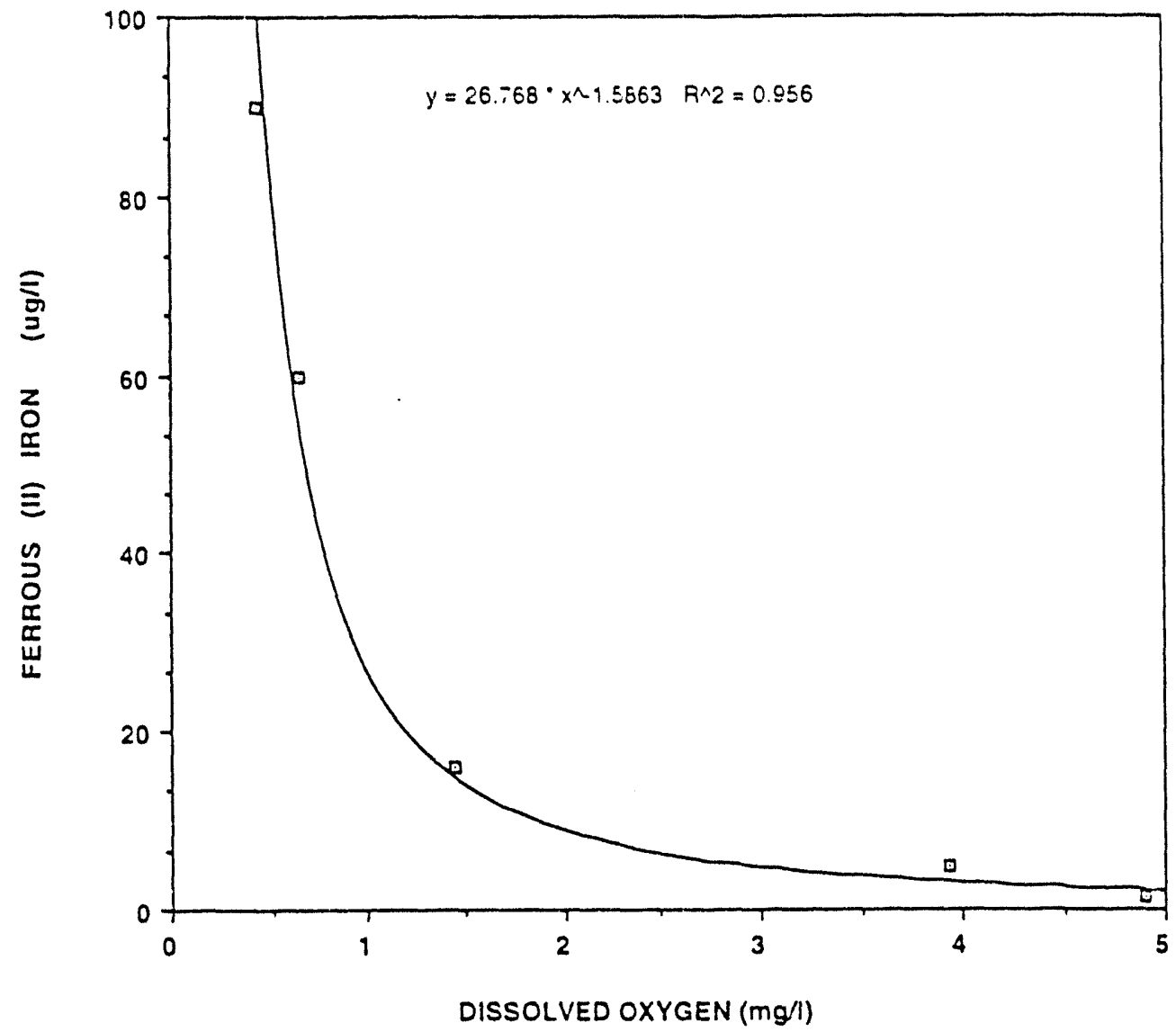

Figure 7 Correlation of ferrous (II) iron and dissolve oxygen concentrations in CRL groundwaters - August 1993. 

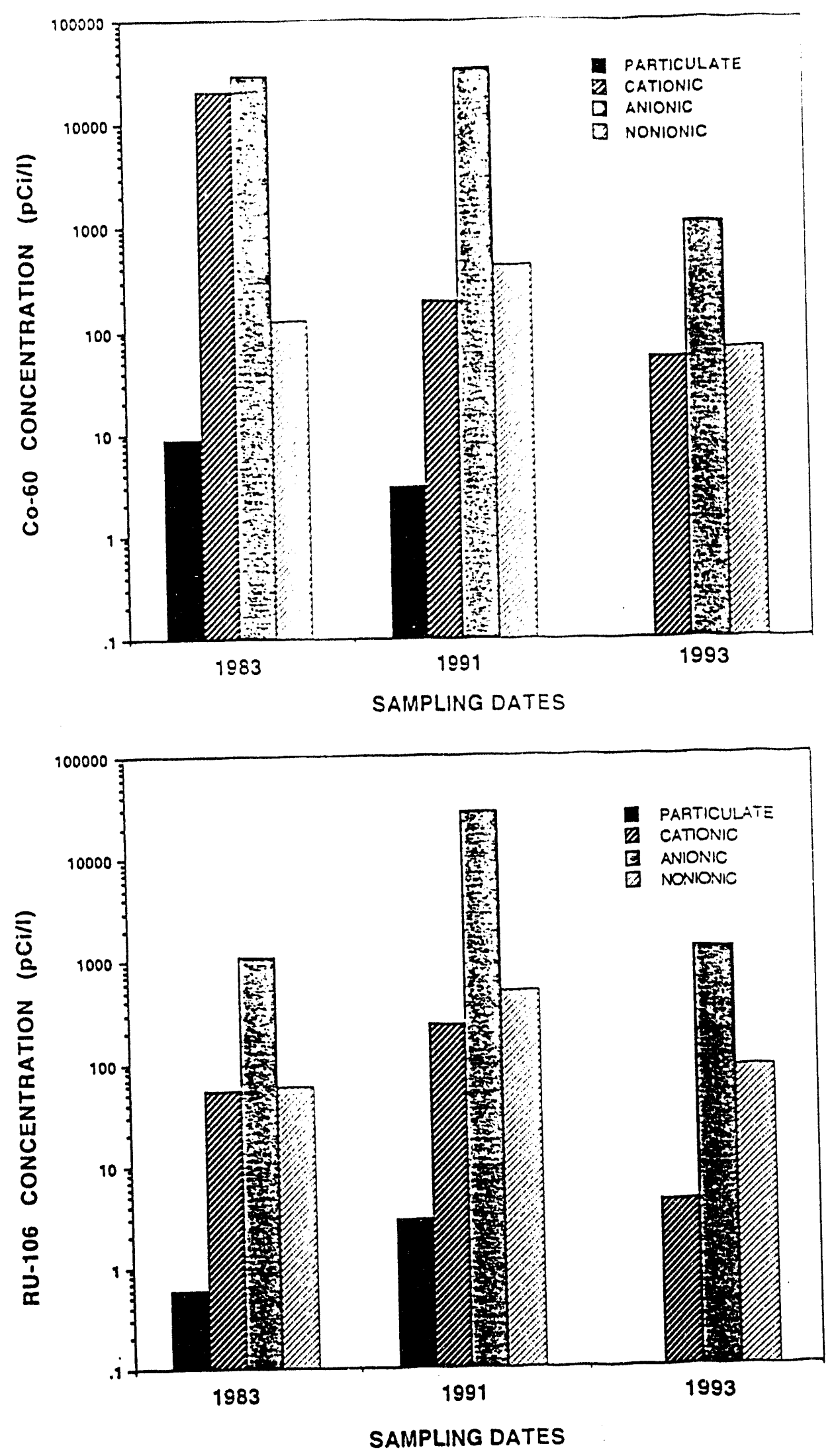

Figure 8 Cobalt-60 and ruthenium-106 concentrations and chemical forms at sampling well Es-16 at the chemical pit groundwater plume. 


$$
\text { - วunโ โd }
$$

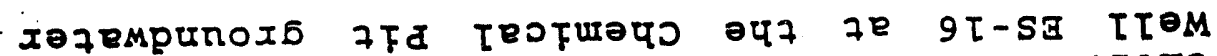

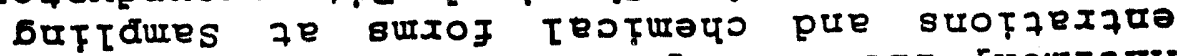

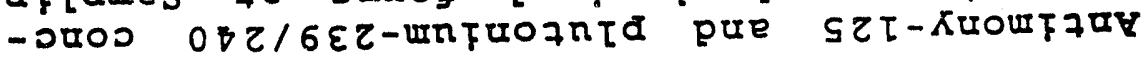

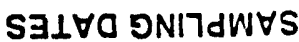

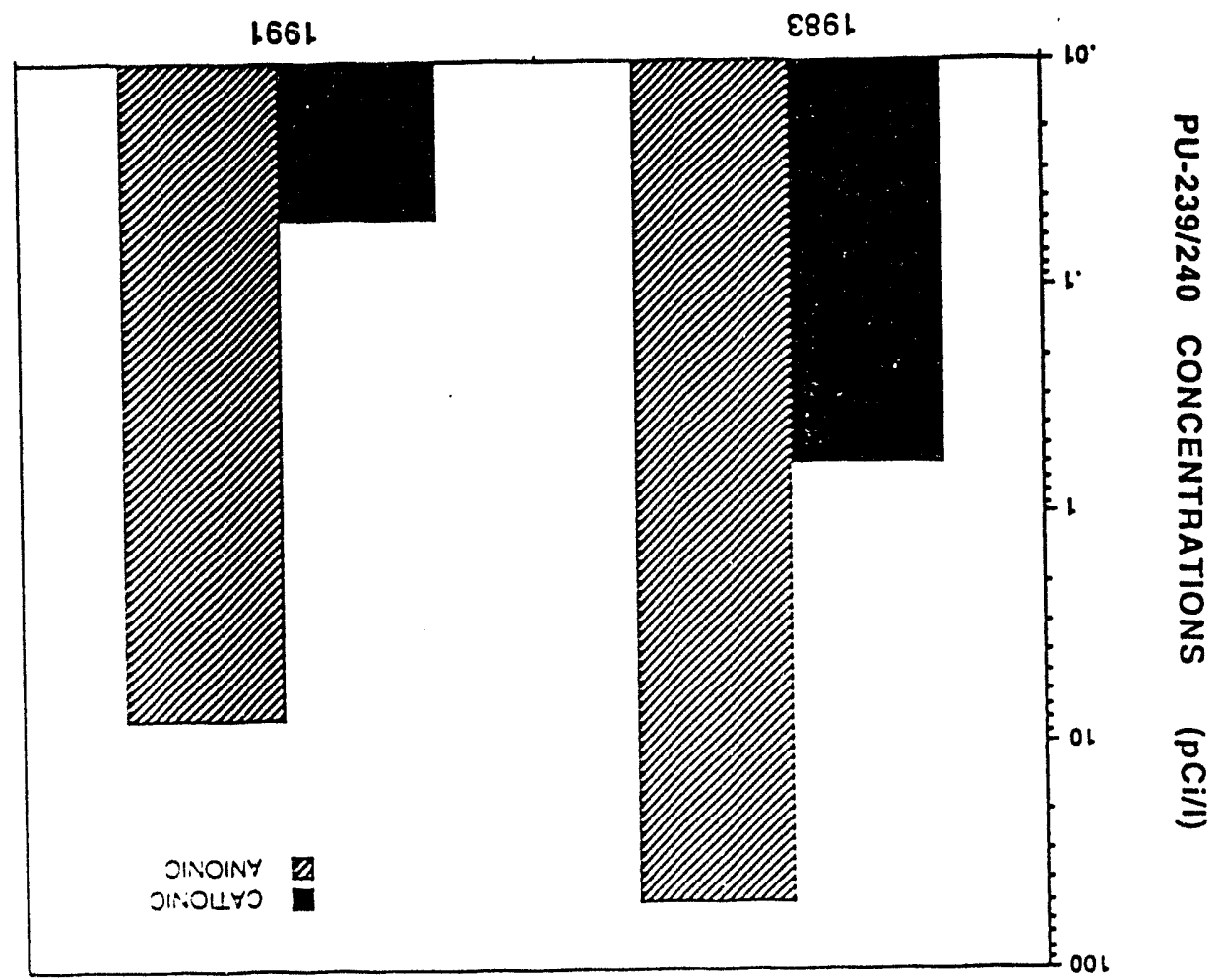

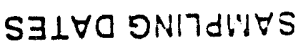

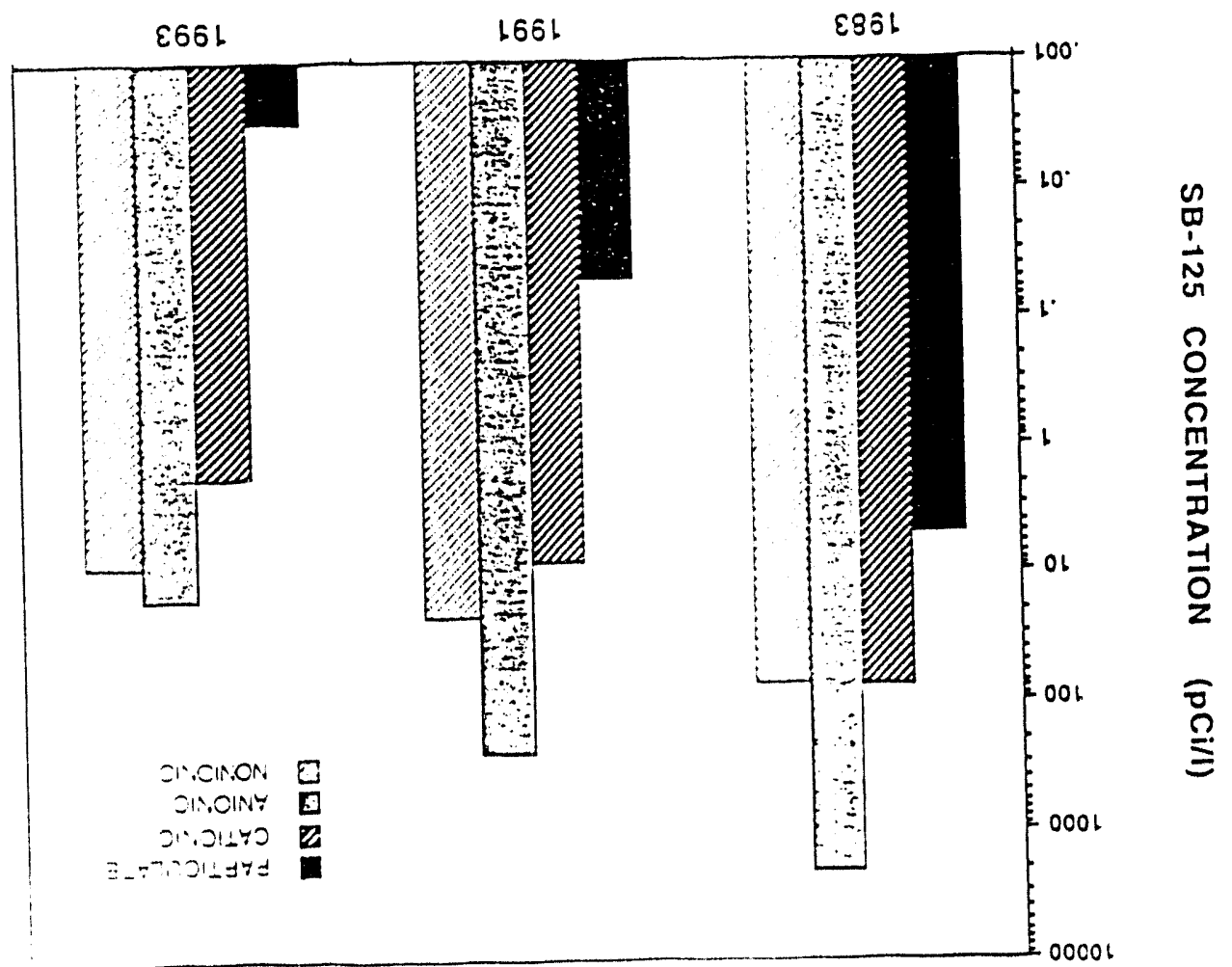




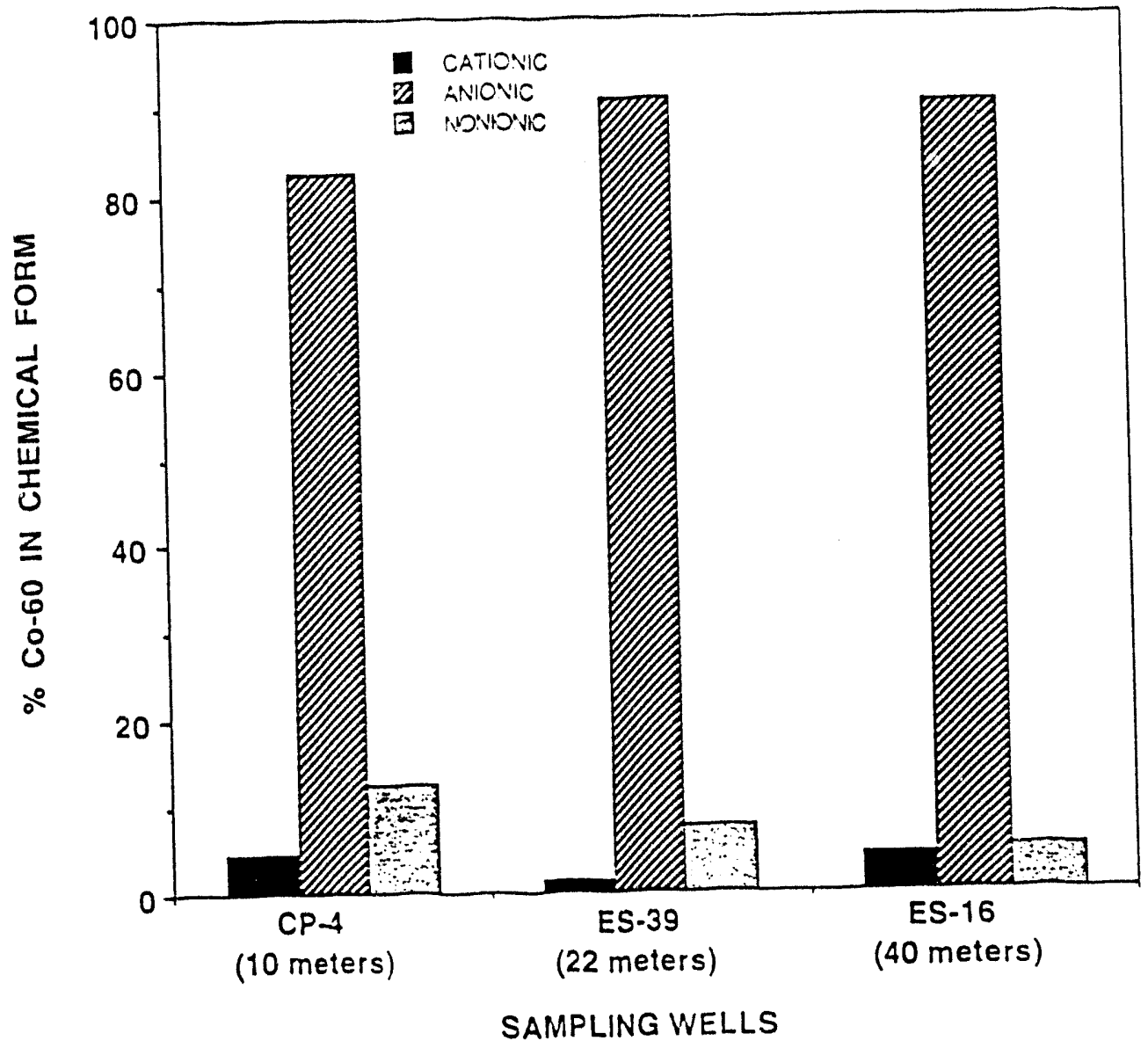

Figure 10 percentage of $C 0-60$ in various chemical forms in the CRI Chemical Pit groundwater plume as a function of distance from the pit. 

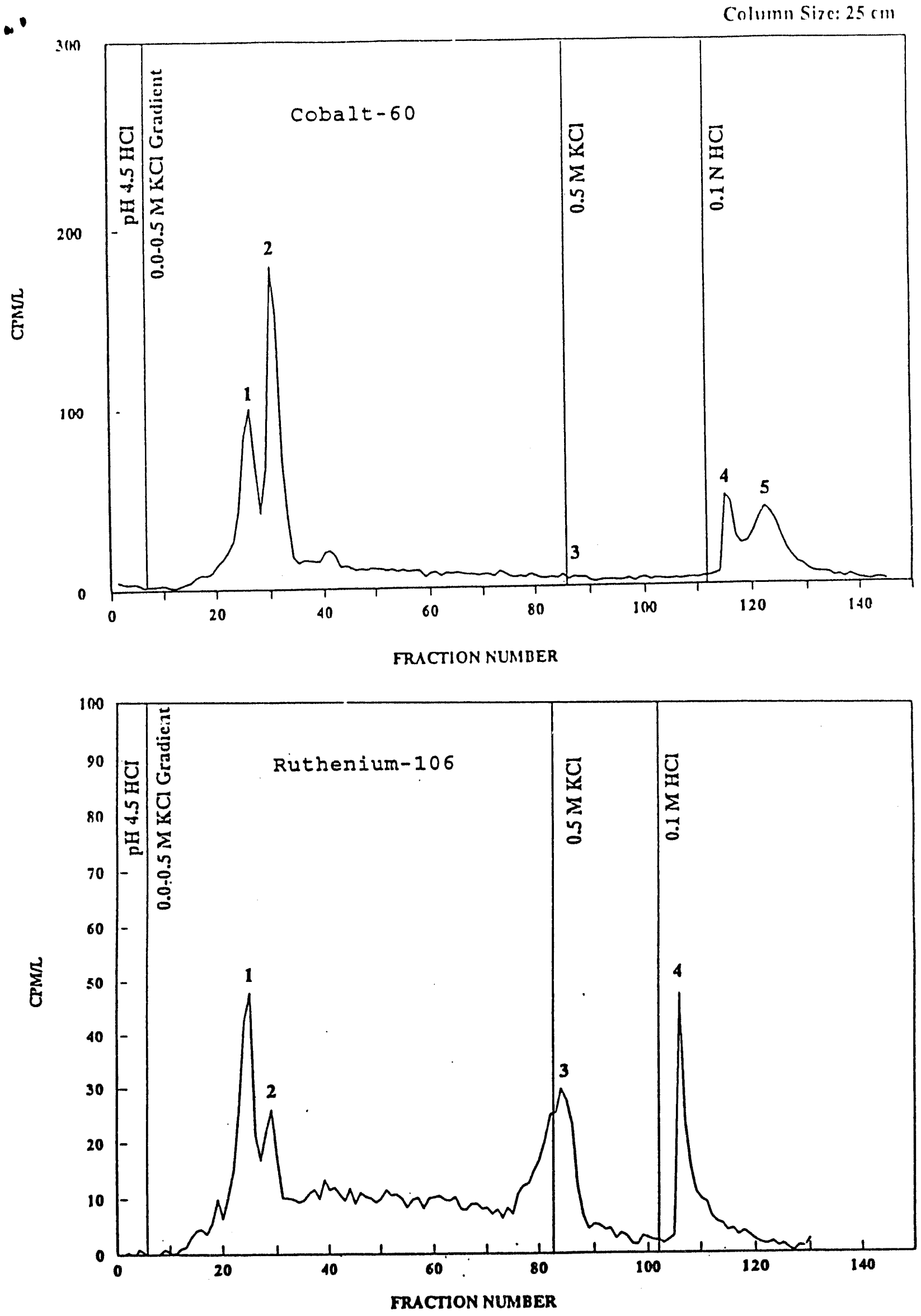

Figure 11 Anion chromatography separation of Co-60
and Ru-106 species from ES-16 groundwater 
W. $4^{\circ}$

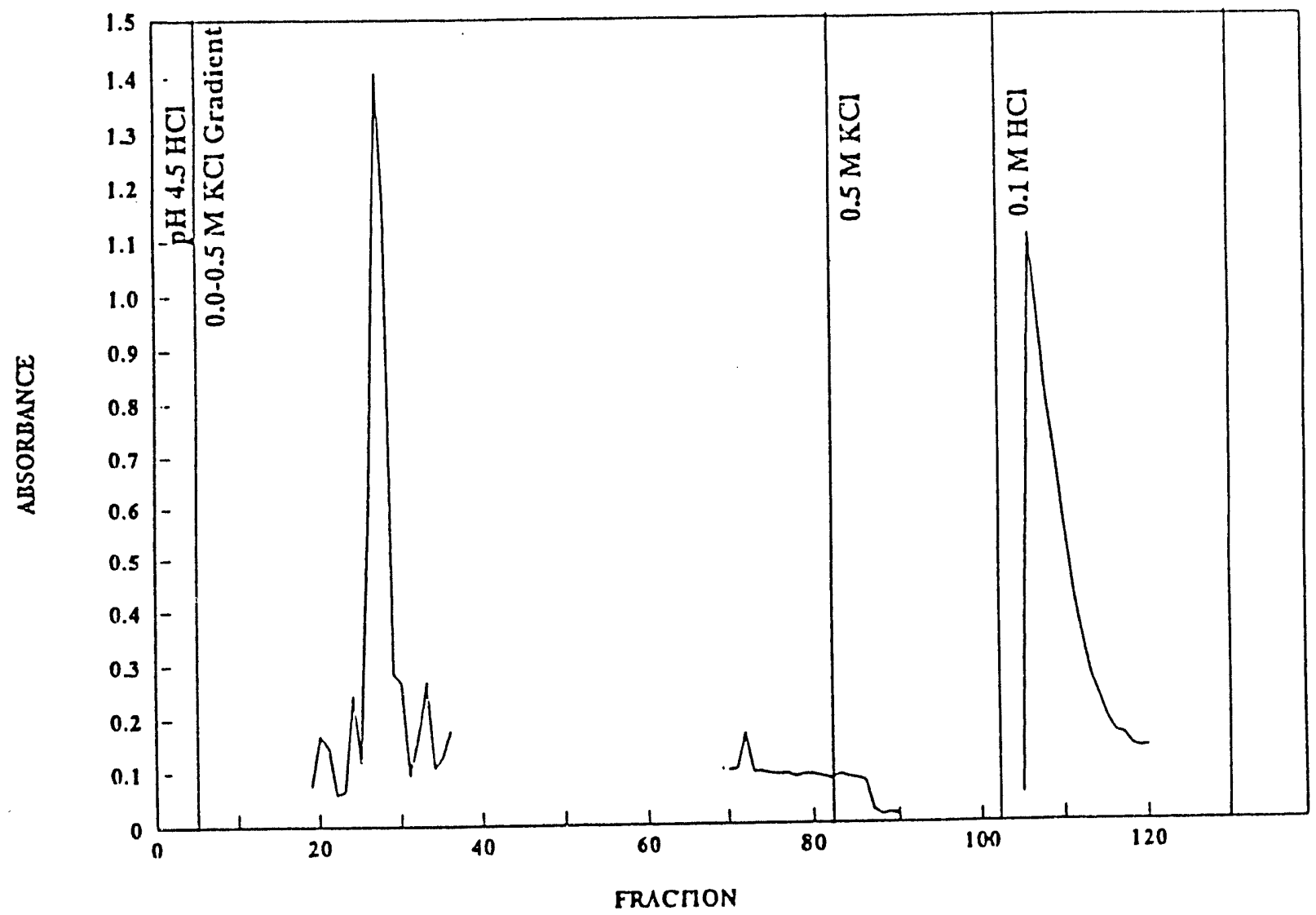

Figure 12 Anion chromatography of ES-16 groundwater measuring ultraviolet absorbance at $254 \mathrm{~nm}$ 

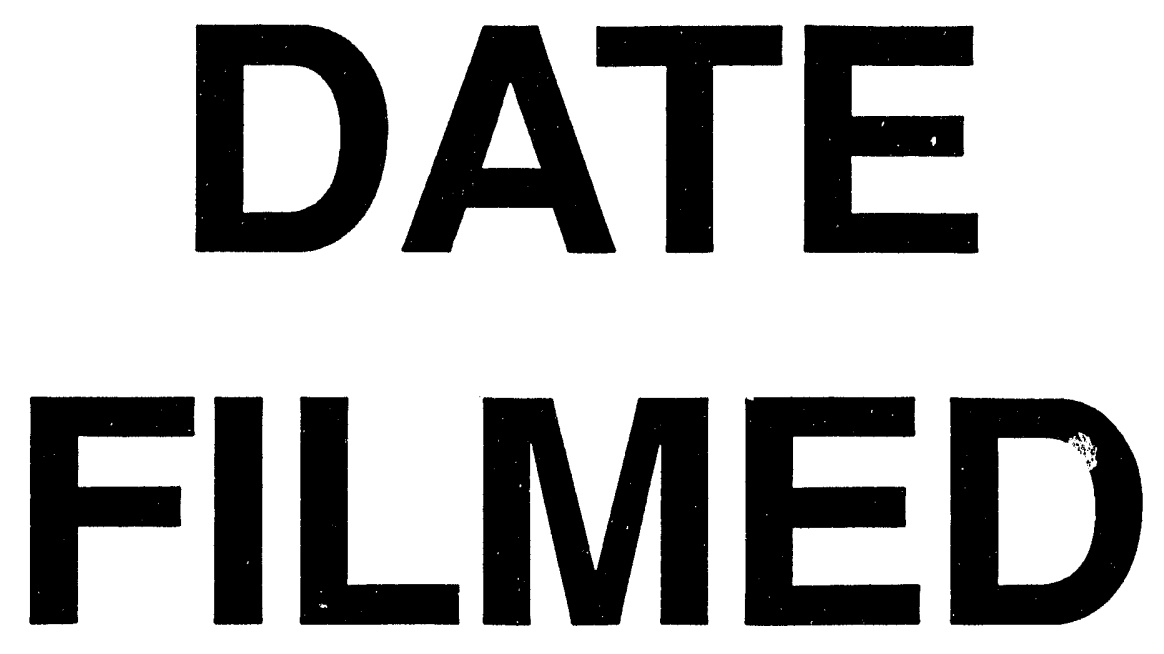

$8 / 23 / 94$
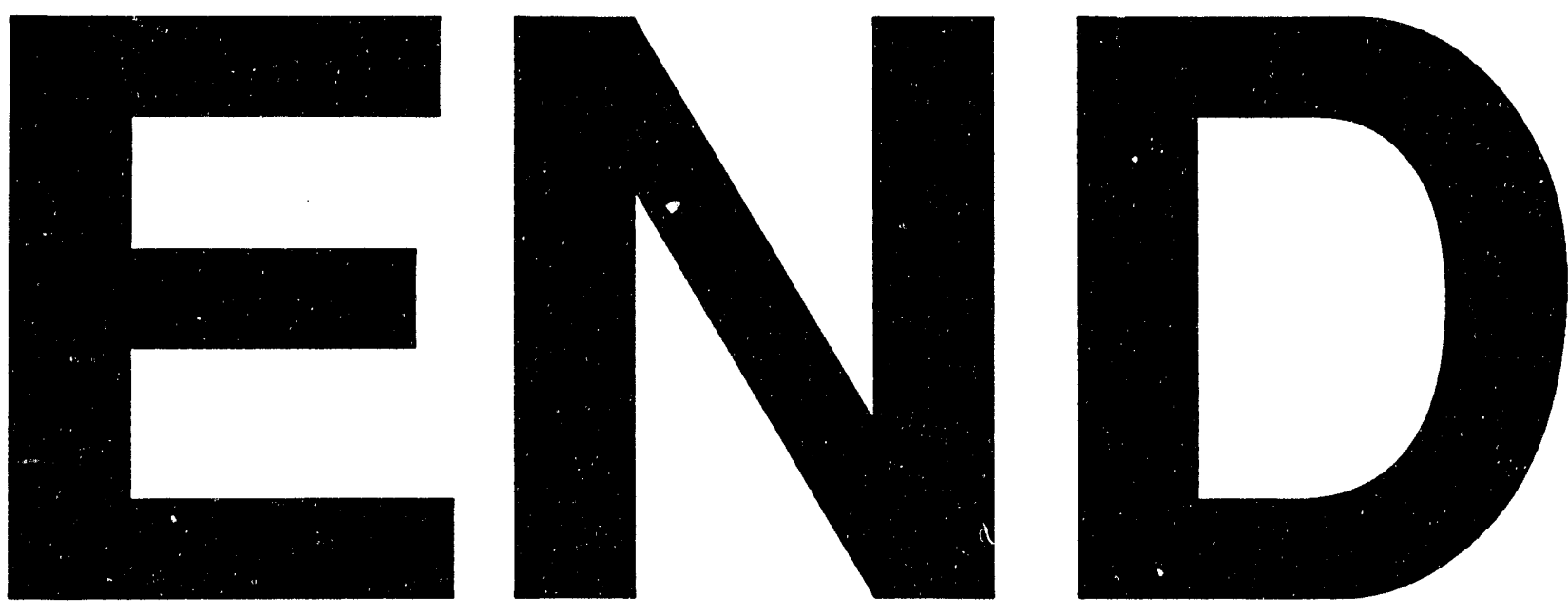
